\title{
STUDY OF UNDERSTANDING OF CONTRADICTIONS OF COMIC CONTENT BY GRADE SCHOOL STUDENTS
}

\author{
Tatiana Vasilyevna Artemyeva \\ Kazan (Volga Region) Federal University, Kremlyovskaya Street, 18, Tatarstan, 420008, Kazan, Russia
}

Received 2014-03-10; Revised 2014-04-12; Accepted 2014-09-08

\begin{abstract}
Annotation: Tasks with comic content are especially difficult for the thinking of children, as they have to resolve the contradiction and inconsistence with their expectations. The article provides an analysis of cognitive mechanisms of understanding comic texts; emphasizes the role of dialectic thinking at resolution of problematic and contradictory situations, statement of colliding properties and relations of an object. The undertaken research is oriented to revealing the acts of dialectic thinking, which participate in the understanding of comic texts by grade school students. The experimental research involved a set of methods for studying the acts of dialectic thinking of grade school students: The Opposites methodology; the study of dialectic act of unification; the methodology of the research of the content seriation; Dialectic Stories. During the research, the students demonstrated the ability to change the habitual system of explanation stating connections between pictures in a series in the reverse order, thus turning the original sense of the situation represented by the pictures into opposite. The grade school students turned out to be able to carry out transition from one alternative to another; to go beyond the context of the existing situation by getting a new angle on the subject. It was revealed that grade school students faced difficulties in finding the colliding relations of an object, a substance. Their sensitivity to contradictions was studied using the Coping Humor Scale and the Pictures Arrangement subtest by D. Wechsler. The inability of grade school students to realize and restore the internal mental content of the character, his thoughts, motives, goals hindered the understanding of the humorous sense of the situation, led to misunderstanding of the cause and effect relationship, on which the narrative events were based. The correlative study confirmed our assumption that dialectic-thinking acts are involved in the understanding of comic, contradictory situations: The acts of unification, content seriation and alternative replacement.
\end{abstract}

Keywords: Contradictions, Humorous Texts, Dialectic Acts, Grade School Students

\section{INTRODUCTION}

The modern society produces strict requirements to the intellectual development of children. The educational technology is oriented to the development of thinking of the school-aged children. In order to achieve this goal, it is necessary to reveal the peculiarities of the understanding by schoolchildren of the behavior of other people, to teach them to handle contradictory and questionable information, to identify different options of its interpretation and to handle several viewpoints with regard to the same phenomenon simultaneously (Tsukermann et al., 2005; Akhmetzyanova, 2013).

The research of the intellectual development of children is provided using various materials: Intellectual tasks, metaphors, mind-teasers, which involve the humor element for sophistication of the intellectual tasks.

The timeliness of the fulfilled research is determined by the fact that comic texts are a special type of intellectual tasks. The function of the humor 
element is not only entertainment and creation of favorable emotional background, but also creation of a certain obstacle, which upsets the logic of the task. The tasks with comic content are especially difficult for children, as they can be understood only if they manage to identify the inconsistence, the contradiction, which is understood as deviation or difference from common expectations.

The qualitative analysis of the cognitive structure of various types of comic texts carried out by Shcherbakova and Osorina (2009) proved that their specificity resided in the existence of the twodimensional content. This two-dimensionality manifests itself in the intercrossing of two contexts, within which the thinking of the tested person functions. One of such systems is based on the conventional or most expected interpretation of the narrative collision represented by the joke-its understanding does not require special mental efforts. The other plan of understanding as well as the other system of reference are less obvious and are not directly semantically close to the first context. Its actualization in the mental space of the tested person is the result of creative transformation of the original conditions, their mental restructuring based on collection of special "tips that have been intentionally integrated by the joke author into its cognitive structure" (Shcherbakova and Osorina, 2009).

Key words or phrases can act as such tips if they have multiple meanings and if they are included in both of the crossing contexts due to their polysemy (Artemyeva, 2013).

Full understanding of the contradictions of comic texts is achieved by holding both systems of reference within the mental field with the focus on the point, in which they cross each other, as well as by the free mental movement between these systems and inside them (Shcherbakova and Osorina, 2009).

For successful solution of the mental task, which is represented by the comic text, it is necessary for the tested person to reproduce the problematic situation in his mental space as precisely and completely as possible: The characters involved in it, the connections and the relations between them, as well as their symbolic meaning. Initially, this problematic situation is represented verbally and the recipient is to represent it in the form of personalized mental representations. It is the completeness and quality of the translation of the original content into the internal psychic language of the spatial structures that the success of their mental handling and subsequently, the completeness of understanding the idea of the comic text depend on. The more precise the consistence of the subjectively generated representations to the original verbal content is, the more complete and qualitative will be the understanding (Kholodnaya, 2004).

Psychological research of domestic and foreign scientists emphasizes the participation of the dialectic thinking, which is able to reveal contradictions of the reality as the internal source of any change and development, in the process of productive transformations of problematic and contradictory situations. The research works by Veraksa, Bagdosarova, Bayanova, Belatutskaya, Krasheninnikova, Shiyan and Shiyan revealed that the basis of the mechanism of dialectic thinking is the handling opposition relations: Transformation, mediacy, dialectic transition, circulation, unification, change of alternatives, according to which the dialectic intellectual acts are identified (Veraksa and Van Oers, 2011; Veraksa, 2006; 2010; Bayanova, 2013).

As the basis of the dialectic thinking mechanism is the handling of opposition relations, the transformation of a problematic contradictory situations, in which the child states the existence of colliding properties and relations, we assumed that dialectic acts are to be engaged in the understanding of contradictions and inconsistencies of comic tasks. The fulfilled research is oriented to revealing the acts of dialectic thinking, which participate in the understanding of contradictions of comic tasks by grade school students.

About 45 children from a Kazan secondary school at the age of 8-10 took part in the research.

\section{MATERIALS AND METHODS}

The Coping Humor Scale developed by (Martin, 1996; 2003) and adapted by (Artemyeva, 2013; 2011; 2012) was used for the purposes of studying the children's usage of humor.

The Picture Arrangement subtest from the test battery by D. Wechsler was used for studying sensitivity to contradictions.

A battery of methodologies was used for revealing the extent of formation of dialectic acts of children: "Opposites" (Bayanova, 1996); research of dialectic act of unification; methodology of studying the content seriation (Veraksa, 2010); "dialectic stories" (Shiyan, 2011). 


\section{RESULTS}

The Coping Humor Scale methodology was used for studying the humor usage by grade school students. $62 \%$ of the tested persons showed high level of humor usage. Children with higher indexes according to this methodology are more optimistic and self-confident. Good sense of humor does not only give a child emotional comfort, but also helps to adapt in a group. Such children are more popular among their peers, manage hardships easier and are resistant to stress. About 17 tested persons (38\%) seriously perceived events happening to them and use humor in stressful situations less often.

The Dog, Milk, Worms layouts of the Wechsler's Picture Arrangement subtest were used for studying the peculiarities of the understanding of contradictions by grade school students. About 37 tested persons (82\%) in the Dog layout and 36 tested persons (80\%) in the Milk layout correctly placed cards, integrated the humorous context in this sequence and managed to understand the contradictory nature of the situation. Along with the method of colliding the interests of animals and people, which a child can understand, the collisions of higher level are used in the Worms layout for creating the comic effect, based on the collision of the behavior of different people. This method turned out to be the most difficult for children, as people, if compared to animals, have a larger number of freedom degrees. Consequently, in situations, in which several people are involved, there is a potentially larger number of development options than in those with one person and an animal involved. $16 \%$ of the tested persons (7 children) failed to handle the Worms layout; they failed to restore the main characters' internal mental content: Thoughts, motives, goals, by their expressed, directly described acts. The inability to realize the internal mental space of a character hindered the understanding of the humorous sense of the situation, led to misunderstanding of the cause and effect relationship, on which the narrative events were based.

The research targeting studying the way children understand comic tasks gives reason to say that humorous content of a task is an additional difficulty that hinders understanding of the text. Children who took into account only the expressed acts of the characters shown on the image at solving a task and did not catch their internal mental content (thoughts, motives, ideas) could not identify any inconsistency in the acts of the characters, realize the presence of the humorous element of the situation and take it into account when reproducing the sense of the situation.

Study of the dialectic acts of grade school students targeted revealing the children's abilities to identify the significant attributes of items, the skill to state the colliding relations in the object, the connections between story lines in a series both in direct and reverse order. The ability of grade school students to mental transition from one alternative to another was to be determined.

The Opposites methodology was used for studying the ability of a child to state connections between items. It was revealed that 29 tested persons $(64 \%)$ were able to reveal the reasons and the substance of connections between items, able to separate the significant attributes of an item, determine its place among other concepts and state the connection with other items.

Using the methodology of studying the dialectic act of unification, we determined the skill of children to state colliding relations of an object. The tested persons were asked questions that assumed existence of contradictory properties with the same object. The research revealed that $80 \%$ of grade school students could identify the colliding relations with an object, but they believed that the object was either in one state, or in the other that was contradictory to the former, but not simultaneously (the first level of carrying out the act of unification). Only $20 \%$ of children noticed the interpenetration of opposite relations demonstrating the second level of carrying out the act of unification.

The methodology of studying the content seriation allowed detecting the extent of formation of dialectic handling. The children were suggested a battery of narrative pictures in direct and reverse order. Depending on how developed the ability of children to think dialectically was, their narrations reflected their cyclic recepts of the transition of the state or phenomenon to its reverse. The first level of handling was revealed with one child (the child could name items or phenomena drawn in the pictures without making a connection between them); the second level was revealed with 6 children (the children listed items or phenomena in reverse order without making connection between them); the third level was revealed with 9 children (the children made connections between some of the pictures in the battery, omitting few of them at that); the fourth level- 
complete handling-was demonstrated by 29 children. These children made connections between all pictures in the series in reverse order, thus turning the original sense of the situation represented in the pictures to the opposite. Thus $65 \%$ of schoolchildren having high level of formation of dialectic handling demonstrated the ability to change the habitual system of explanation of a process or a phenomenon.

The study of the dialectic mental act of the alternative change was performed using the Dialectic Stories methodology, which allowed revealing the ability of the grade school students to mental transition from one alternative to another. Seventy one percent of the tested persons ( 32 children) carried out transition from one alternative to another; turned out of be able to step out of the context of the existing situation, to get a new, often contradictory angle on the subject of the phenomenon. Twenty two percent of the tested persons (10 children) suggested one variant of solution. Seven percent of the tested persons (3 children) did not manage to make out with the task and failed to resolve the problematic situation.

\section{DISCUSSION}

The grade school students faced difficulties at identifying colliding relations within an object believing the object to be either in one state or in another opposite to the former, but not simultaneously in both states. Sixty five percent of the schoolchildren demonstrated the ability to change the habitual system of process explanation by stating connections between the pictures in a battery in the reverse order, thus turning the original sense of the situation represented by the pictures into the opposite. The majority of grade school students ( $72 \%$ of the tested persons) turned out to be able to carry out transition from one alternative to another; to step out of the context of the existing situation by getting a new contradictory angle on the subject of the phenomenon.

For revealing the dialectic acts engaged in the understanding of comic texts by grade school students, the correlative analysis was used (by Pearson). In the result of this analysis, it was revealed that there were significant connections between the studied dialectic acts: The dialectic act of unification and the content seriation $(r=0.719, p=0.01)$; the content seriation and the dialectic act of alternative change $(r=0.566, p=0.01)$; the dialectic act of unification and the dialectic act of alternative change $(\mathrm{r}=0.587, \mathrm{p}=0.01)$.
The direct interrelation between the usage of humor and the dialectic act of unification was revealed $(\mathrm{r}=$ $0.815, \mathrm{p}=0.01$ ), which gives reason to say that the dialectic act of unification at understanding humorous context allows children to step out of the formal logic and find opposites in the observed object.

A direct interrelation between usage of humor and the dialectic act of seriation was detected at $(r=0.703, p=$ 0.01). It points to the fact that the dialectic act of seriation enables children to identify at understanding a humorous situation the opposite elements at the beginning of the situation and upon its completion.

A direct interrelation between humor and the dialectic act of alternative change was also determined $(\mathrm{r}=0.533, \mathrm{p}=0.01)$. According to our assumptions, it can be connected with the fact that the dialectic act of alternative change enables grade school students at understanding of humorous situations to step out of the context of the existing situation and to get a new, contradictory angle on the item or the phenomenon.

The correlative study confirmed our assumption that dialectic acts are involved in the understanding of comic, contradictory situations: The close correlative connections were stated between humor and the dialectic act of unification. It was revealed that the dialectic acts of seriation and alternative change enabled grade school students to understand the inconsistency of a situation, a story line and relations of characters.

\section{CONCLUSION}

- The ability of grade school children to understand contradictions and inconsistencies of humor material is determined by the extent of formation of their dialectic thinking: The acts of unification, content seriation and alternative change

- The dialectic act of unification with understanding of the humor context enables children to step out of the formal logic and detect contradictions in the observed phenomenon recording them simultaneously

- The dialectic act of seriation allows identifying the opposite elements at the beginning and the end of the comic situation

- The dialectic act of alternative change allows grade school students to step out of the context of the existing situation and get a new contradictory angle on the subject or the phenomenon 


\section{REFERENCES}

Akhmetzyanova, A.I., 2013. The specifics of anticipatory consistency in children with speech pathology. Middle-East J. Sci. Res., 16: 927-931. DOI: 10.5829/idosi.mejsr.2013.16.07.11956

Artemyeva, T.V., 2011. About the method of studying coping humor and its opportunities. Kazan Pedagogic J., Kazan. Magarif Publishing House, 4: 118-123.

Artemyeva, T.V., 2012. Understanding of humor and dialectic acts-studying the interrelation. Edu. SelfDev. Kazan: Center Innovative Technol., 5: 114117.

Artemyeva, T.V., 2013. Peculiarities of primary school children figurative speech. Comprehension World Applied Sci. J., 27: 738-741. DOI: 10.5829/idosi.wasj.2013.27.06.13709,

Bayanova, L.F., 1996. Contradiction and childish thinking: Educational and instructional guide. Birsk BSPI, pp: 32.

Bayanova, L.F., 2013. Vygotsky's hamlet: The dialectic method and personality psychology. Psychol. Russia State Art, 1: 35-42.

Kholodnaya, M.A., 2004. Cognitive Styles: On the Nature of Individual Mentality. 2nd Edn., Piter, Saint Petersburg, pp: 384.

Martin, R.A., 1996. The Situational Humor Response Questionnaire (SHRQ) and Coping Humor Scale (CHS): A decade of research findings. Humor Int. J. Humor Res., 9: 251-272. DOI: 10.1515/humr.1996.9.3-4.251
Martin, R.A., 2003. Sense of Humor. In: Positive Psychological Assessment: A Handbook of Models and Measures, Lopez, S.J. and C.R. Snyder (Eds.), American Psychological Association, Washington, DC., ISBN-10: 1557989885, pp: 313-326.

Shcherbakova, O.V. and M.V. Osorina, 2009. The humorous element as the factor of sophistication of intellectual tasks (As Exemplified by D. Wechsler's Test). Herald Saint Petersburg University.

Shiyan, I.B., 2011. Dialectic stories. Obruch, 1: 13-16.

Tsukermann, G.A., I.V. Yermakova, G.N. Kudina and O.V. Sokolova, 2005. Understanding contradictions: Microanalysis of the PISA-200 test tasks. Psychol. Sci. Edu., 1: 51-64.

Veraksa, N.E., 2006. Dialectic Thinking. Vatant, Ufa, pp: 212.

Veraksa, N.E., 2010. Structural approach to dialectic cognition: Psychology in Russia. State Art, 3: 227-239.

Veraksa, N.E. and B. Van oers, 2011. Early childhood education from a Russian perspective. Int. J. Early Years Edu., 19: 5-17. DOI: 10.1080/09669760.2011.570995 